\title{
EVALUASI KAPABILITAS PROSES MANAGE PROBLEMS COBIT 5 PADA DASI-JR
}

\author{
${ }^{1}$ Megawati, ${ }^{2}$ Eva Khasana \\ ${ }^{1,2}$ Program Studi Sistem Informasi, Fakultas Sains dan Teknologi, UIN Suska Riau \\ Jl. HR Soebrantas, KM. 18.5, No. 155, Simpang Baru, Pekanbaru, Indonesia, 28293. \\ E-mail : ${ }^{1}$ megawati@uin-suska.ac.id, ${ }^{2}$ Eva.Khasana@Students.uin-suska.ac.id
}

\begin{abstract}
ABSTRAK
DASI-JR (Data Korporasi) merupakan sistem informasi yang bertujuan untuk membantu kegiatan operasional pada PT. XYZ dalam mengelola data-data yang terintegrasi antara data-data iuran wajib, sumbangan wajib, pelayanan, dan keuangan. DASI-JR terintegrasi dengan data-data yang berada di kantor Perwakilan, kantor Cabang dan data-data yang berada di kantor Pusat. Adapun permasalahan dalam penggunaan sistem DASI-JR yaitu petugas sering salah dalam menginputkan nomor urut resi pembayaran Iuran Wajib Penumpang Kendaraan Bermotor Umum (IWKBU) ke dalam sistem DASI-JR dikarenakan dalam penginputan nomor urut resi masih dilakukan secara manual dan sistem DASI-JR masih dirasa lambat untuk diakses karena sering terjadi permasalahan jaringan. Dalam penelitian ini domain proses yang digunakan adalah DSS03 (Manage Problems) dan responden ditentukan dengan menggunakan RACI chart (responsible, accountable, consulted and informed). Dari hasil analisis yang telah dilakukan berdasarkan COBIT 5 Process Assessment Model (PAM), tingkat kapabilitas proses manage problems pada sistem DASI-JR berada pada level 2 sebesar 77,35\% dengan status Largely Achieved (L). Hal ini menunjukkan bahwa kriteria secara garis besar sudah tercapai, dan telah terdapat fakta atau bukti atas pendekatan sistematis dan pencapaian yang signifikan atas kriteria tersebut, namun masih ada beberapa kelemahan. Untuk meningkatkan level kapabilitas pada PT. XYZ, diberikan usulan rekomendasi perbaikan berdasarkan proses-proses dari setiap atribut yang ada.
\end{abstract}

Kata Kunci: COBIT 5, DASI-JR, Manage Problems, PAM.

\section{A. PENDAHULUAN}

Semakin berkembangnya teknologi informasi menuntut perusahaan untuk melakukan pengembangan internal maupun eksternal organisasi [1]. Teknologi informasi (TI) merupakan bagian yang sangat penting bagi perusahaan maupun instansi dan juga merupakan suatu nilai investasi untuk menjadikan perusahaan tersebut menjadi lebih baik serta mendukung rencana strategis perusahaan atau instansi untuk mencapai visi, misi serta tujuan yang diinginkan [2].

Setiap perusahaan berupaya untuk menerapkan suatu teknologi informasi yang dapat memenuhi kebutuhan perusahaan dalam mencapai tujuannya [2]. Layanan teknologi informasi yang tepat waktu, akurat, dan relevan dengan kebutuhan pengguna merupakan hal yang sangat penting diperhatikan dalam mendukung kelancaran pelaksanaan aktivitas suatu organisasi termasuk institusi pemerintahan [3].

PT. XYZ telah menggunakan sistem informasi dalam memproses kegiatan operasionalnya. Salah satu sistem yang di gunakan oleh PT. XYZ adalah DASI-JR. DASI-JR diterapkan pada tahun 2014. Sistem DASI-JR sangat membantu untuk menunjang kinerja pegawai dalam melakukan pelayanan. Namun, berdasarkan hasil wawancara yang dilakukan kepada pengguna DASI-JR, sistem DASI-JR ini masih terdapat beberapa permasalahan. Permasalahan yang ada pada sistem DASI-JR dapat dilihat pada Tabel 1 .

Tabel 1. Latar Belakang Masalah

\begin{tabular}{|c|c|c|}
\hline No. & Masalah Yang Dihadapi & Domain \\
\hline 2. & $\begin{array}{l}\text { Petugas sering salah dalam } \\
\text { menginputkan no urut resi pembayaran } \\
\text { IWKBU ke dalam sistem DASI-JR } \\
\text { dikarenakan dalam menginputkan no } \\
\text { urut ini masih dilakukan secara manual, } \\
\text { jika no urut resi salah di inputkan } \\
\text { petugas harus membatalkan resi yang } \\
\text { salah dengan menjalankan prosedur } \\
\text { yang ada. } \\
\text { Sistem DASI-JR masih dirasa lambat } \\
\text { untuk diakses karena sering terjadi } \\
\text { permasalahan jaringan dan server yang } \\
\text { digunakan untuk mengakses sistem } \\
\text { DASI-JR tidak bisa digunakan oleh } \\
\text { banyak user sekaligus. }\end{array}$ & $\begin{array}{c}\text { Deliver, } \\
\text { Service } \\
\text { and } \\
\text { Support } \\
03 \\
\text { (Manage } \\
\text { Problems) }\end{array}$ \\
\hline $\begin{array}{l}\text { eb } \\
\text { Co } \\
\text { ect }\end{array}$ & $\begin{array}{l}\text { ol Objective for Information } \\
\text { logy), ITIL (The IT Infrastruct } \\
\text { ISO/IEC } 17799 \text { (The } \\
\text { ization for Standardization/The } \\
\text { technical Commision) dan lainn }\end{array}$ & $\begin{array}{l}\text { a sistem } \\
\mathrm{k} \text { dapat } \\
\text { melainkan } \\
\text { lui service } \\
\text { kup lama. } \\
\text { an di PT. } \\
\text { Untuk itu } \\
\text { DASI-JR. } \\
\text { i terdapat } \\
\text { COBIT } 5 \\
d \text { Related } \\
\text { Library), } \\
\text { ernational } \\
\text { ernational }\end{array}$ \\
\hline
\end{tabular}


Dalam penelitian ini menggunakan kerangka kerja COBIT 5. COBIT 5 merupakan salah satu kerangka bisnis dalam tata kelola manajemen perusahaan, dengan mengkombinasikan tata kelola perusahaan dan teknik manajemen. Pada COBIT 5 juga menyediakan prinsip, analisis serta model yang berfungsi untuk membantu dalam meningkatkan kepercayaan dan nilai dari sistem informasi [4]. Penelitian ini bertujuan untuk mengetahui tingkat kapabilitas sistem DASI-JR pada proses manage problems dan memberikan rekomendasi perbaikan dalam menyelesaikan permasalahan yang terjadi.

\section{B. LANDASAN TEORI}

\section{B.1. Evaluasi}

Evaluasi merupakan salah satu rangkaian kegiatan dalam meningkatkan kualitas, kinerja, atau produktifitas suatu lembaga dalam melaksanakan programnya. Melalui evaluasi akan diperoleh informasi tentang apa yang telah dicapai dan apa yang belum dicapai. Selanjutnya, informasi ini digunakan unutk perbaikan suatu program [5].

\section{B.2. COBIT 5}

COBIT 5 merupakan generasi terbaru dari panduan ISACA yang membahas mengenai tata kelola dan manajemen IT. COBIT 5 dibuat berdasarkan pengalaman penggunaan COBIT selama lebih dari 15 tahun oleh banyak perusahaan dan pengguna dari bidang bisnis, komunitas IT, risiko, asuransi, dan keamanan. COBIT 5 membantu perusahaan menciptakan nlai optimal dari TI dengan menjaga keseimbangan antara menyadari manfaatnya dan mengoptimalkan tingkat risiko serta penggunaan sumber daya [4].

COBIT 5 menyediakan referensi model proses yang mewakili semua proses yang bisa ditemukan dalam suatu perusahaan terkait dengan kegiatan TI. Model proses yang diusulkan bukan hanya sekedar model proses tetapi suatu model yang bersifat komprehensif. Setiap perusahaan harus mendefinisikan bidang prosesnya sendiri, dengan mempertimbangkan situasi tertentu dalam perusahaan terseut. COBIT 5 juga menyediakan kerangka kerja untuk mengukur dan memantau kinerja TI, berkomunikasi dengan layanan dan mengintegrasikan praktik pengelolaan terbaik [4].

\section{B.3. Process Assessment Model (PAM)}

PAM dikembangkan untuk mengatasi kebutuhan penilaian berbasis proses COBIT untuk meningkatkan ketelitian dan keandalan ulasan proses IT. PAM adalah model kemampuan proses dua dimensi. Dalam satu dimensi, dimensi proses, proses didefinisikan dan diklasifikasikan ke dalam kategori proses. Dalam dimensi lain, dimensi kemampuan, satu set atribut proses dikelompokkan ke dalam tingkat kemampuan yang terdefinisi. Atribut proses memberikan karakteristik terukur dari kemampuan proses [6].

\section{B.4. DSS03 Manage Problems}

Proses DSS03 Manage Problems berfokus pada pengidentifikasian dan pengklasifikasian masalah dan penyebabnya serta menyediakan resolusi dengan jangka waktu untuk mencegah terulangnya insiden dan memberikan rekomendasi untuk perbaikan [7].

Tujuan dari proses ini adalah meningkatkan ketersediaan, memperbaiki level layanan, mengurangi biaya, dan meningkatkan kenyamanan pelanggan, serta kepuasan dengan mengurangi jumlah problem operasional. Dalam DSS03 terdapat 5 Management Practice sebagai berikut: (1) DSS03.01 (Identify and classify problems). Pendefinisian dan penerapan prosedur untuk melaporkan masalah yang teridentifikasi, termasuk klasifikasi masalah, kategorisasi dan prioritas; (2) DSS03.02 (Ivestigate and diagnosa problems). Menyelidiki dan mendiagnosa masalah untuk menilai dan menganalisa akar penyebab masalah; (3) DSS03.03 (Raise known errors). Begitu akar penyebab masalah diidentifikasi, membuat catatan known errors dan mengidentifikasi solusi yang tepat; (4) DSS03.04 (Resolve and close problems). Identifikasi dan mengajukan solusi berkelanjutan terhadap akar penyebab masalah, meningkatkan permintaan perubahan melalui proses manajemen perubahan yang telah ditetapkan jika diperlukan untuk menyelesaikan kesalahan (error). Memastikan bahwa personil sadar akan tindakan yang dilakukannya dan mempunyai rencana yang dikembangkan untuk mencegah terjadinya insiden dimasa depan; (5) DSS03.05 (Perform proactive problem management). Mengumpulkan dan menganalisis data operasional (terutama catatan insiden dan perubahan) untuk mengidentifikasi gejala yang muncul yang mungkin menunjukkan masalah. Membuat catatan masalah untuk memungkinkan penilaian jika diperlukan untuk memecahkan error. Memastikan bahwa personil sadar akan tindakan yang dilakukannya dan mempunyai rencana yang dikembangkan untuk mencegah terjadinya peristiwa-peristiwa dimasa depan.

\section{METODOLOGI PENELITIAN \\ C.1. Perencanaan}

Pada tahapan ini kegiatan yang dilakukan adalah merumuskan masalah yang terjadi pada sistem DASI-JR. Setelah dirumuskan, kegiatan selanjutnya menentukan tujuan untuk memperjelas 
kerangka tentang apa saja yang menjadi sasaran dari penelitian ini.

Dari rumusan masalah dan tujuan yang telah dibuat, maka ditentukan domain yang akan digunakan pada penelitian. Domain yang digunakan adalah DSS03 manage problems yang berfokus pada pengidentifikasian dan pengklasifikasian masalah dan penyebabnya serta menyediakan resolusi untuk mencegah terulangnya insiden.

Kegiatan selanjutnya adalah menentukan RACI chart untuk menentukan jumlah responden yang akan digunakan pada penelitian. Kemudian melakukan studi pustaka untuk mendapatkan teoriteori yang dapat dijadikan pedoman dalam melakukan penelitian. Studi pustaka dilakukan dengan mempelajari buku dan jurnal-jurnal yang berkaitan dengan penelitian.

\section{C.2. Pengumpulan Data}

Pengumpulan data pada penelitian ini dilakukan dengan cara observasi langsung ke lapangan, wawancara, dan penyebaran kuesioner. Wawancara dilakukan kepada pengguna sistem dengan mengajukan pertanyaan-pertanyaan yang berkaitan dengan penilitian. Kuesioner disebarkan kepada responden yang sudah ditentukan berdasarkan RACI chart.

\section{C.3. Pengolahan dan Analisis Data}

Kegiatan yang dilakukan pada tahap ini adalah melakukan pengukuran level kapabilitas pada sistem DASI-JR. Pengukuran dilakukan berdasarkan jawaban dari masing-masing responden pada kuesioner yang telah disebarkan. Setelah level kapabilitas diketahui, maka selanjutnya membuat rekomendasi perbaikan berdasarkan hasil temuan untuk menyelesaikan permasalahan yang ada pada sistem DASI-JR.

\section{ANALISA DAN PEMBAHASAN}

\section{D.1. Analisa Sistem DASI-JR Saat Ini}

DASI-JR merupakan sistem informasi yang bertujuan untuk membantu kegiatan operasional pada PT. XYZ dalam mengelola data-data yang terintegrasi antara data-data iuran wajib, sumbangan wajib, pelayanan, dan keuangan. DASI-JR terintegrasi dengan data-data yang berada di kantor Perwakilan, kantor Cabang dan data-data yang berada di kantor Pusat. Gambar 1 merupakan halaman login dari sistem DASI-JR.

Sistem DASI-JR digunakan oleh semua pegawai, namun setiap pegawai memiliki tampilan menu yang berbeda-beda sesuai dengan tugas dan tanggung jawabnya masing-masing. Sistem DASIJR berada dibawah tanggung jawab Kabag Operasional. Pada Sistem DASI-JR terdapat 4 menu yaitu: (1) Menu File. Di dalam menu file terdapat 3 sub menu yaitu login, ganti kantor dan parameter umum; (2) Menu Admin Sistem. Menu ini berisi tentang pendelegasian sistem; (3) Menu Pelayanan. Menu ini digunakan untuk menginputkan data laka dan menginputkan data klaim yang harus dibayar oleh PT. XYZ kepada korban kecelakaan; (4) Menu Teknik. Menu ini digunakan untuk penerimaan dari iuran wajib dan penerimaan sumbangan wajib. Iuran wajib berasal dari pembayaran asuransi alat angkutan umum, sedangkan sumbangan wajib berasal dari pemilik kendaraan saat melakukan pembayaran pajak tahunan.

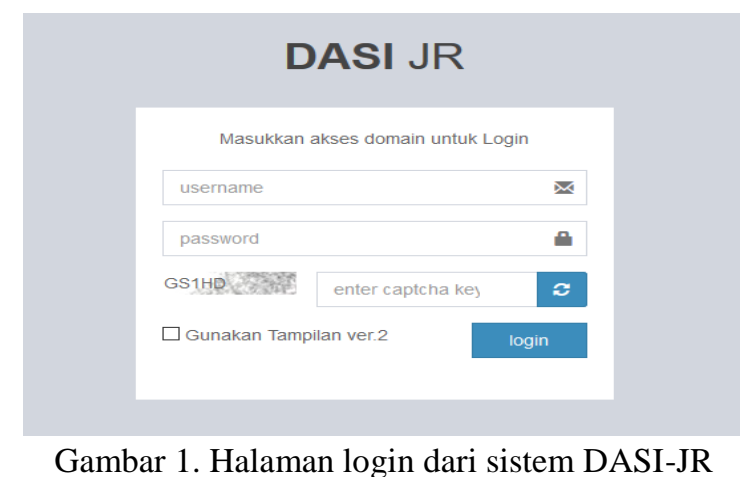

\section{D.2. Pemetaan RACI Chart}

Responden pada penelitian ini ditentukan menggunakan RACI chart (responsible, accountable, consulted and informed). RACI chart merupakan sebuah matrik dari semua aktivitas atau wewenang dalam mengambil keputusan yang dilakukan dalam sebuah organisasi terhadap semua orang atau peran untuk setiap proses [8]. Tabel 2 merupakan pemetaan RACI chart pada proses DSS03 manage problems. Berdasarkan pemetaan RACI didapatkan jumlah responden sebanyak 4 orang yang dapat dilihat pada Tabel 3 .

Berdasarkan tabel ringkasan pencapaian level pada proses DSS03 tersebut, maka didapatkan hasil tingkat kapabilitas proses manage problems yang terjadi pada sistem DASI-JR berada pada level 2 dengan status Largely Achieved (L) sebesar 77,35\% dimana kriteria secara garis besar sudah tercapai, dan telah terdapat fakta atau bukti atas pendekatan sistematis dan pencapaian yang signifikan atas kriteria tersebut, namun masih ada beberapa kelemahan. Hal ini menunjukkan bahwa kegiatan proses manage problems pada sistem DASI-JR belum terkontrol dengan teratur dan belum dikelola dengan baik. Dalam mengatasi masalah yang terjadi pegawai melapor melalui service desk untuk di tindaklanjuti oleh kantor pusat. Kemudian setelah masalah ditangani, kantor pusat akan mengonfirmasi melalui e-mail dan service desk bahwa masalah telah di perbaiki. Namun setelah 
Jurnal Ilmiah Rekayasa dan Manajemen Sistem Informasi, Vol. 5, No. 1, Februari 2019, Hal. 57-61 e-ISSN 2502-8995, p-ISSN 2460-8181

masalah diperbaiki, tidak dilakukan tindakan pengontrolan terhadap masalah yang terjadi, sehingga masalah dapat terulang kembali. Rata-rata pencapaian level pada proses DSS03 dapat dilihat pada Gambar 2.

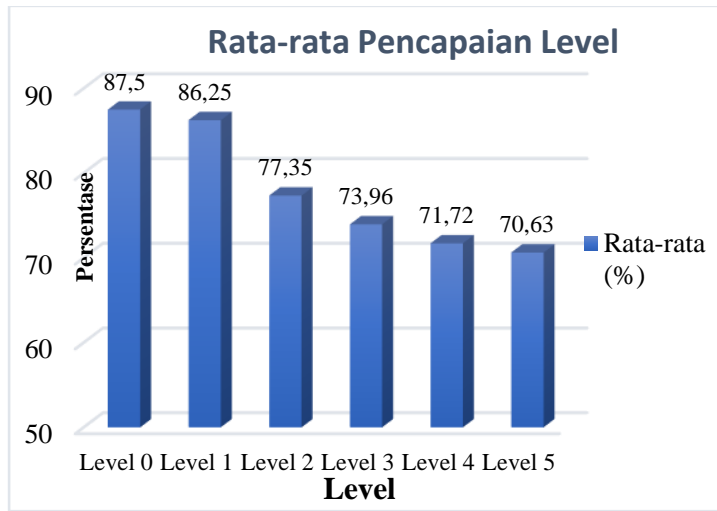

Gambar 2. Rata-rata Pencapaian Level Pada Proses DSS03

Tabel 3. Daftar Responden

\begin{tabular}{lc}
\hline \multicolumn{1}{c}{ Struktur Fungsional PT. XYZ } & $\begin{array}{c}\text { Jumlah } \\
\text { Responden }\end{array}$ \\
\hline Bagian Operasional & 1 \\
Sub Bagian IW & 1 \\
Sub Bagian SW, Humas dan Hukum & 1 \\
Pelaksana & 1 \\
\hline \multicolumn{1}{c}{ Jumlah } & 4 \\
\hline
\end{tabular}

Tabel 2. Pemetaan RACI chart Domain DSS03

\begin{tabular}{|c|c|c|c|c|}
\hline Activity & 离 & 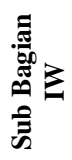 & 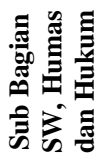 & 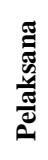 \\
\hline $\begin{array}{l}\text { Identify and classify } \\
\text { problems }\end{array}$ & I & A & $\mathrm{C}$ & $\mathrm{R}$ \\
\hline $\begin{array}{l}\text { Investigate and } \\
\text { diagnose problems }\end{array}$ & A & $\mathrm{C}$ & I & $\mathrm{R}$ \\
\hline Raise known errors & A & $\mathrm{R}$ & $\mathrm{R}$ & $\mathrm{R}$ \\
\hline $\begin{array}{l}\text { Resolve and close } \\
\text { problems }\end{array}$ & I & A & $\mathrm{C}$ & $\mathrm{R}$ \\
\hline $\begin{array}{l}\text { Perform proactive } \\
\text { problem management }\end{array}$ & A & $\mathrm{R}$ & $\mathrm{R}$ & $\mathrm{R}$ \\
\hline
\end{tabular}

\section{D.3. Hasil Pencapaian Level Proses DSS03}

Tabel 4 merupakan ringkasan mengenai hasil pencapaian level beserta rincian persentase mengenai penilaian dari masing-masing proses atribut.

\section{D.4. Rekomendasi Perbaikan}

Rekomendasi perbaikan dibuat dengan menentukan langkah yang perlu dilakukan berdasarkan kriteria yang belum sepenuhnya tercapai. Berikut ini merupakan strategi perbaikan pada setiap proses atribut:

Tabel 4. Ringkasan Pencapaian Level Pada Proses DSS03

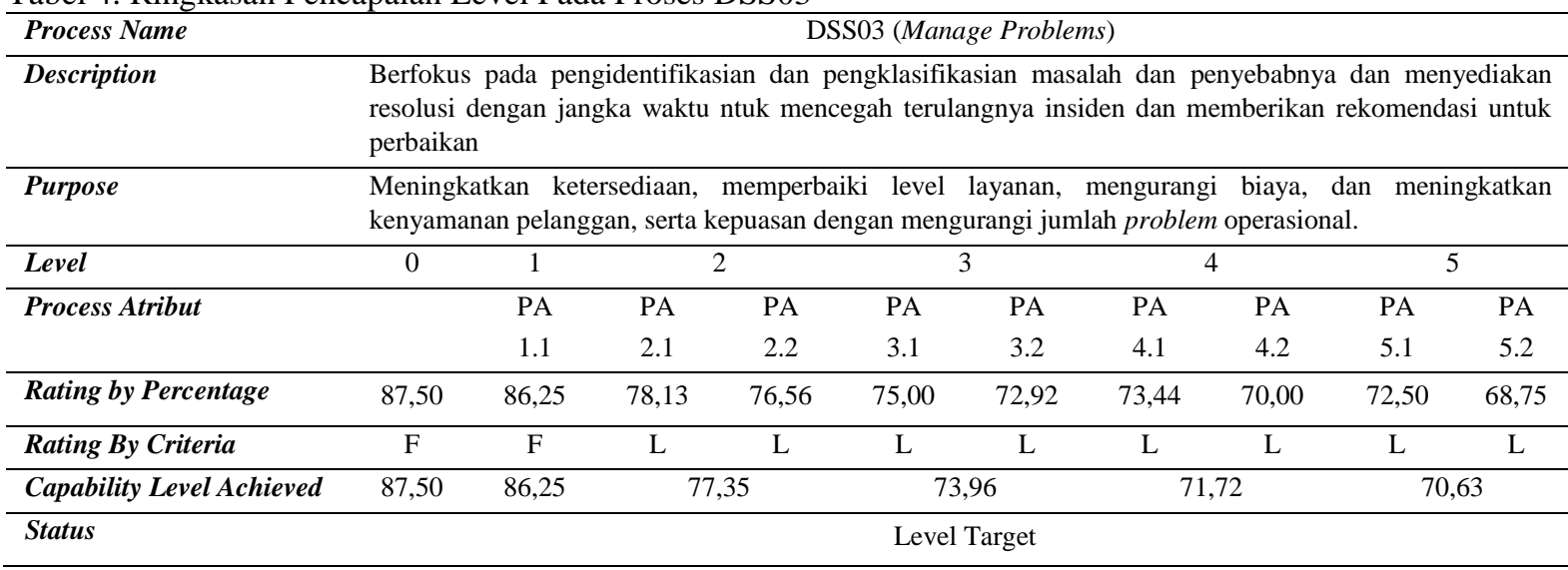

.Tabel 5. Rekomendasi Perbaikan Proses DSS03

\begin{tabular}{|c|c|c|}
\hline No & $\begin{array}{c}\text { Proses } \\
\text { Atribut }\end{array}$ & Rekomendasi Perbaikan \\
\hline 1. & $\begin{array}{l}\text { PA } 2.1 \\
\text { Performance } \\
\text { Management }\end{array}$ & $\begin{array}{l}\text { a. Perlunya pendefinisian secara jelas } \\
\text { mengenai kegiatan proses } \\
\text { pengelolaan masalah dan } \\
\text { dikomunikasikan kepada pihak } \\
\text { yang terlibat agar proses } \\
\text { pengelolaan masalah dapat } \\
\text { dilakukan secara } \\
\text { (DSS03.01). } \\
\text { b. Merencanakan dan memonitor } \\
\text { kinerja proses manage problems } \\
\text { agar penyebab permasalahan dapat } \\
\text { diidentifikasi dengan } \\
\text { (DSS03.02). } \\
\text { c. Perlu adanya penetapan tindakan } \\
\text { yang harus dilakukan ketika proses }\end{array}$ \\
\hline
\end{tabular}

pengelolaan masalah tidak sesuai rencana (DSS03.04).

2. PA 2.2 Work a. Perlu adanya penetapan kriteria Product kualitas untuk penilaian terhadap Management proses pengelolaan masalah yang telah dilakukan (DSS03.05).

b. Adanya dokumentasi hasil kerja proses pengelolaan masalah agar proses pengelolaan masalah dapat dianalisa dan diminimalisir dengan baik (DSS03.05).

c. Dilakukan pengontrolan lebih lanjut terhadap hasil kerja proses pengelolaan masalah yang sudah di lakukan (DSS03.04).

d. Perlu dilakukan peninjauan terhadap hasil kerja apakah sudah 


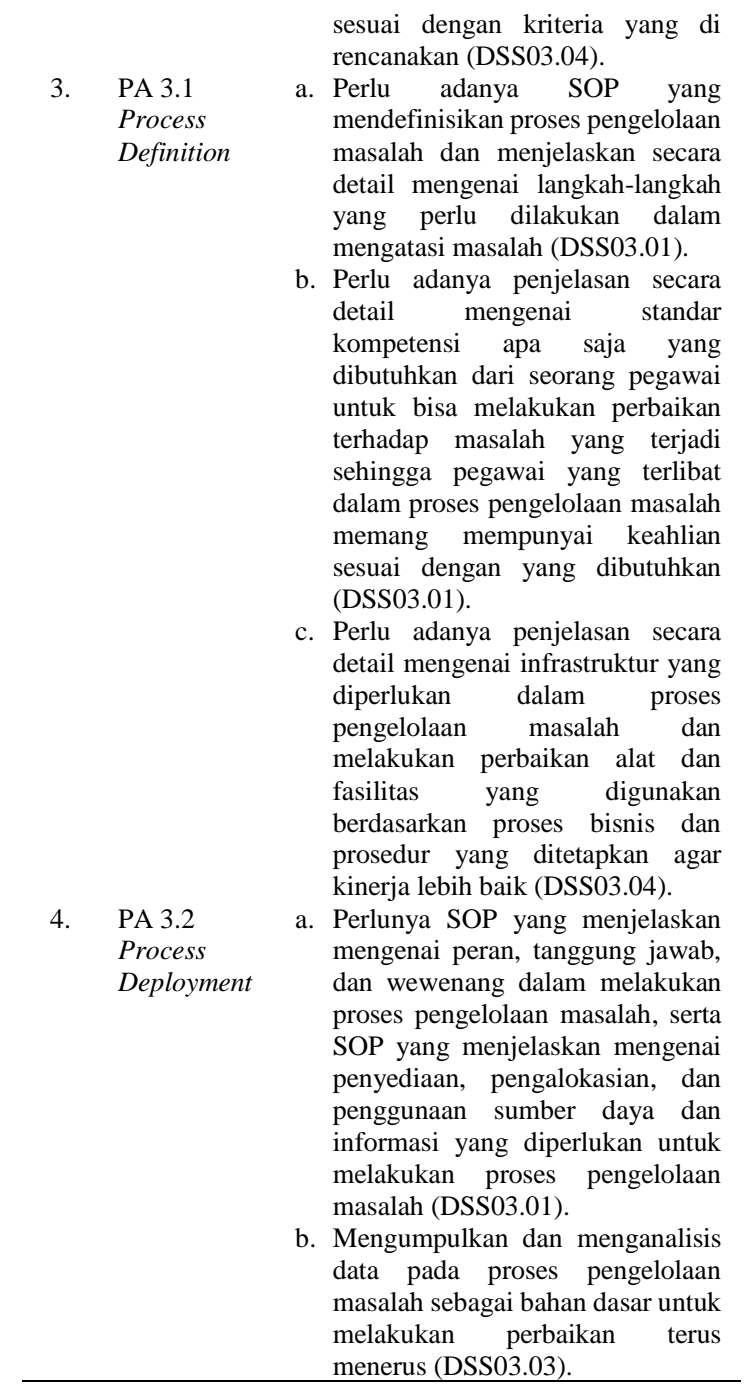

\section{E. KESIMPULAN}

Berdasarkan hasil penelitian yang telah dilakukan pada sistem DASI-JR terkait proses manage problems berdasarkan kerangka kerja COBIT 5 maka dapat diambil kesimpulan yaitu: (1) Hasil tingkat kapabilitas proses manage problems pada sistem DASI-JR berada pada level 2 dengan status Largely Achieved (L) sebesar 77,35\% dimana kriteria secara garis besar sudah tercapai, dan telah terdapat fakta atau bukti atas pendekatan sistematis dan pencapaian yang signifikan atas kriteria tersebut, namun masih ada beberapa kelemahan; (2) Rekomendasi perbaikan yang dapat dilakukan dalam mencapai target tingkat kapabilitas di level 3 adalah sebagai berikut: (a) PA 2.1 Performance Management: mendefinisikan secara jelas mengenai kegiatan proses manage problems dan dikomunikasikan kepada pihak yang terlibat, merencanakan dan memonitor kinerja proses manage problems, serta perlu adanya penetapan tindakan yang harus dilakukan ketika proses manage problems tidak sesuai rencana; (b) PA 2.2 Work Product Management: adanya penetapan kriteria kualitas untuk penilaian terhadap proses pengelolaan masalah yang telah di lakukan, pendokumentasian hasil kerja proses pengelolaan masalah, melakukan pengontrolan lebih lanjut terhadap hasil kerja dan dilakukan peninjauan terhadap hasil kerja apakah sudah sesuai dengan kriteria yang di rencanakan; (c) PA 3.1 Process Definition: membuat panduan dan proses standar (SOP) secara detail yang menjelaskan mengenai langkah-langkah yang perlu dilakukan dalam mengatasi masalah, adanya penjelasan secara detail mengenai standar kompetensi pegawai yang bisa melakukan perbaikan masalah sesuai dengan keahlian, melakukan perbaikan alat dan fasilitas yang digunakan berdasarkan proses bisnis dan prosedur yang ditetapkan; (d) PA 3.2 Process Deployment: perlu adanya SOP yang menjelaskan secara detail mengenai peran, tanggung jawab, dan wewenang dalam melakukan proses pengelolaan masalah, dan yang menjelaskan mengenai penyediaan, pengalokasian, dan penggunaan sumber daya dan informasi. Mengumpulkan dan menganalisis data pada proses pengelolaan masalah sebagai bahan dasar untuk melakukan perbaikan terus menerus.

\section{REFERENSI}

[1] Fajrin, Rati Amanda dkk. 2016. Perancangan Tata Kelola Teknologi Informasi di BAPASI Pemkab Bandung Menggunakan Framework COBIT 5 Pada Domain EDM dan DSS. Journal of Information System Engineering and Business Intelligence. 2(2): 74-80.

[2] Putra, Ricky Darius dkk. 2016. Audit Teknologi Informasi Dengan Menggunakan Framework COBIT 5 Domain DSS (Deliver, Service and Support) Pada PT. Inovasi Tjaraka Buana. E-Proceeding of Engineering. Vol.3: page 930-937.

[3] Noorhasanah dkk. 2015. Evaluasi Tata Kelola Teknologi Informasi Berbasis Framework COBIT 5. Seminar Nasional Teknologi Informasi dan Multimedia.

[4] ISACA. 2012. A Business Framework for the Governance and Management of Enterprise IT.

[5] Megawati dan Rahmayani ,Mentari Tri Indah. 2015. Evaluasi Pengelolaan Website UIN Suska Riau Berdasarkan Framework COBIT 4.1. Eksplora Informatika.

[6] ISACA. 2013. COBIT Process Assessment Model (PAM): Using COBIT 5.

[7] ISACA. 2012. COBIT® 5: Enabling Processes.

[8] IT Governance Institute. 2007. Framework Control Objectives Management Guidelines Maturity Models. 